\title{
LA PROBLEMÁTICA DE LA CONTINUIDAD A TRAVÉS DE LA RUPTURA: LOS CAMBIOS INTERTEÓRICOS EN LOS PROGRAMAS DE INVESTIGACIÓN REALISTA DE LA LINGÜISTICA
}

\author{
JUAN LUIS JiMÉNEZ RuIZ \\ Universidad de Alicante \\ Jiménez@ua.es
}

\begin{abstract}
Resumen
El presente artículo constituye un intento de establecer los parámetros de aproximación entre diferentes tendencias especializadas en métodos y objetivos al análisis del cambio interteórico desde las bases del objetivismo y de organizar los resultados obtenidos desde diferentes campos del conocimiento en los canales epistemológicos adecuados.

PALABRAS CLAVE: Cambio interteórico, estudio dinámico, Epistemologia, Historiografia lingüistica, Paradigma realista.
\end{abstract}

\begin{abstract}
The present paper constitutes an attempt to establish the parameters within specialized trends in approach, methods or aims, in order to place the analysis of intertheoretical change within the boundries of objetivism, and to organize in adequate epistemological channels the results achieved from differents fields of knowledge.

KEY WORDS: Inthertheoretical change, Dynamic analysis, Episthemology, Linguistic historiography, Realistic paradigm.
\end{abstract}

\section{Preliminares}

Como hemos manifestado en otra ocasión', los fenómenos diacrónicos son susceptibles de dos niveles diferentes de análisis que van a determinar las razones que posibilitan el cambio tanto teórico como modélico en la investigación lingüística: uno cinemático y otro dinámico.

Según Díez \& Moulines (1999: 442), el análisis cinemático se centra en la descripción de las entidades involucradas en el cambio y de las formas y tipos de cambios de las mismas; el análisis dinámico, por contra, se ocupa de las causas o factores desencadenantes de los diversos tipos de cambios.

El estudio tanto de la dinámica como de la cinemática del cambio en los patrones de la investigación lingüística tiene su ubicación disciplinaria en el marco de la Historiografía como vertiente diacrónica de la Epistemología de la Lingüística porque en ella se aglutina la tarea descriptiva analítica del estudio cinemático con el carácter empírico del análisis dinámico.

1 Nos referimos a un trabajo que presentamos en el homenaje ofrecido al profesor Molina Redondo durante el $\checkmark$ Congreso Andaluz de Lingüística General, celebrado en la Facultad de Filosofia y Letras de la Universidad de Granada y que actualmente se encuentra en prensa; Cf. Jiménez Ruiz, 2005. 
En el esquema adjunto representamos la ubicación disciplinaria de ambos tipos de estudio.

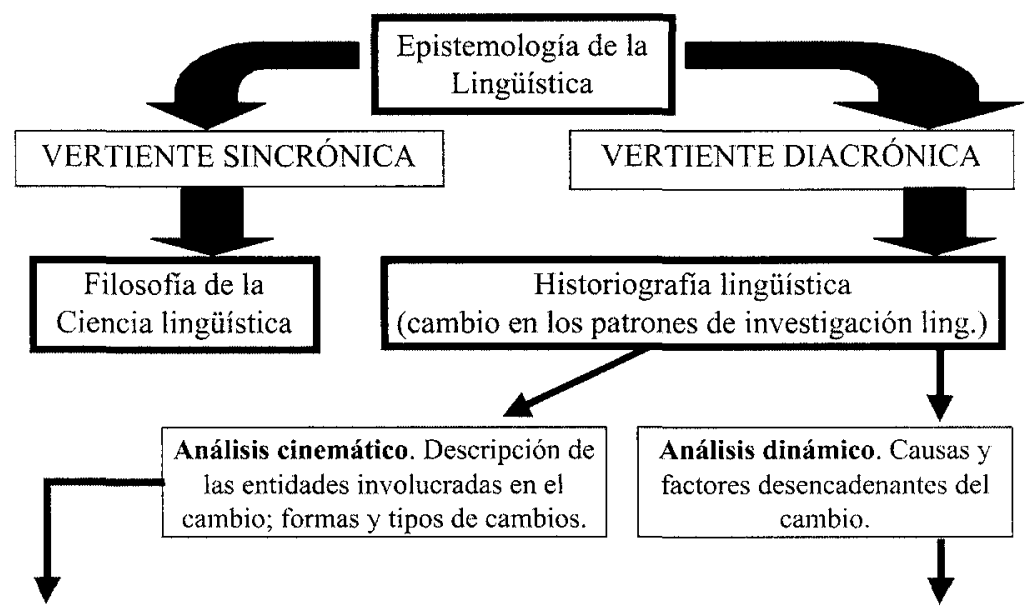

La historia lingüística como un proceso estructural de diferentes ciclos en los que los

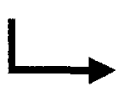
distintos programas de investigación realistas e idealistas se oponen a partir de un a serie de bases ontológicas sobre el lenguaje.

Para desarrollar metodológicamente estos dos tipos de cambios que se han producido en la investigación lingüística a lo largo de la historia propusimos un doble acercamiento; a saber, opositivo, a partir de un análisis cinemático que establece los procesos cíclicos que ponen en relación los distintos momentos de crisis — González de Oleaga, 1996: 475-501-, esplendor, y transitorio que posibilita el resurgir de una nueva crisis $\mathrm{y}$, por tanto, el inicio de otro proceso cíclico similar; y lineal que, en este caso, a partir de un estudio dinámico nos permitía poner en relación cada uno de los distintos momentos (de crisis, esplendor y transitorio) de los ciclos establecidos, con el fin de comprender en su justa medida la reelaboración lingüística evolutiva.

Estos acercamientos se basan en la proposición de una visión epistemológica de la historia lingüística como un proceso estructural de diferentes ciclos en los que distintos programas de investigación realistas e idealistas se oponen a partir de una serie de bases ontológicas sobre el lenguaje subyacentes ${ }^{2}$. Con ella pretendemos dar respuesta a los dos fenómenos diacrónicos más básicos de toda reflexión epistemológica; a saber, el de la problemática de la identidad a través del cambio y el de la problemática de la continuidad a través de la ruptura.

2 La concepción de cualquier objeto de estudio tiene, en palabras de Bunge, dos componentes, uno metodológi¿o, basado en la manera de estudiar este objeto, en las «guías» para elaborar ciencia, que diria Estany (1993: 27). y otro ontológico, centrado en esta ocasión en la naturaleza del mismo, a partir de concepciones sociológicas y, en general, científicas y filosóficas; cf. Bunge, 1980: 20 y ss. 


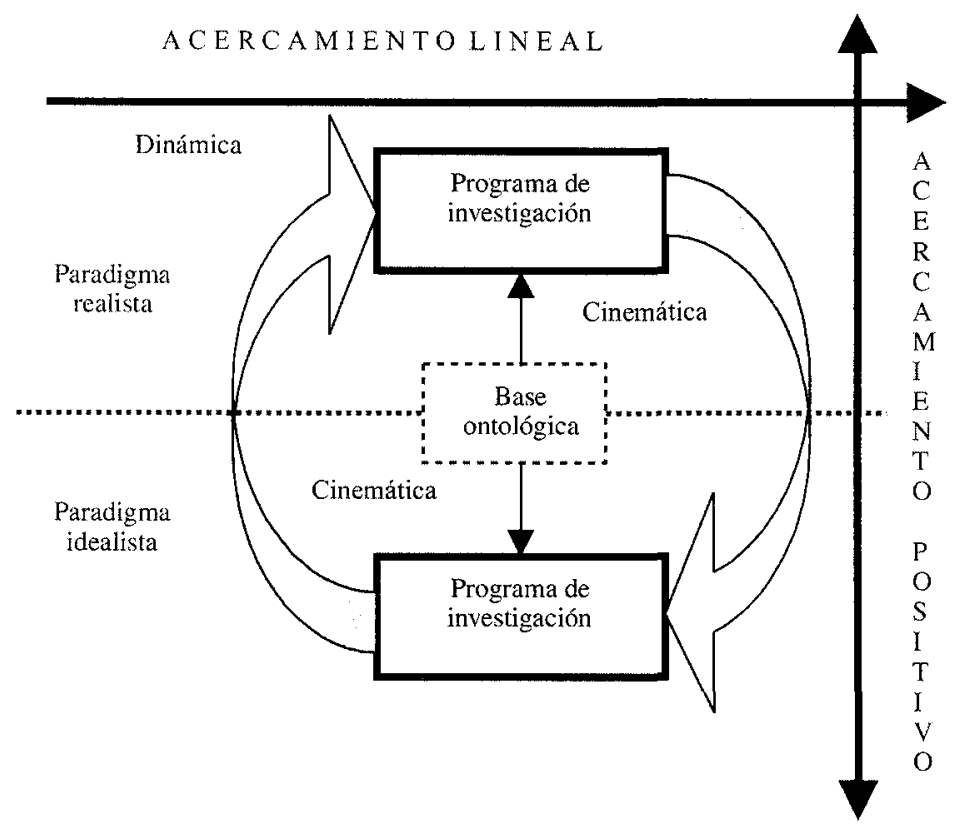

Para Díez \& Moulines (1999: 441), el primero consiste en adjudicar a cada programa de investigación una identidad a pesar de las modificaciones a que están sometidos en el transcurso del tiempo histórico. Ello se produce gracias a una propiedad que poseen los programas de investigación. Se trata de la genidentidad o identidad diacrónica, que posibilita el acercamiento opositivo a lo largo de la historia a partir del estudio cinemático, consistente, en dar cuenta de los cambios profundos, cambios que han producido una auténtica revolución, con el consiguiente desplazamiento y sustitución de teorías y modelos de los distintos programas de investigación ${ }^{3}$.

El segundo fenómeno - el de la continuidad a través de la ruptura-consiste en el análisis diacrónico de la naturaleza y estructura de las teorías y modelos de los distintos programas de investigación lingüistica en tanto que entidades temporales, a lo largo de los diferentes ciclos epistémicos, precisando las causas determinantes de los diversos tipos de cambios. Esta evolución permite el acercamiento lineal a partir ahora de un análisis dinámico.

Veamos, pues, los presupuestos de ambos acercamientos.

El acercamiento opositivo a partir del análisis cinemático pretende dar cuenta del primer fenómeno histórico mencionado con anterioridad; esto es, el de la identidad a través del cambio. Es lo que en Filosofía de la ciencia se conoce como cambio intrateórico y que concebimos siguiendo a Laudan (1986) como una tradición de investigación o de resolución de

3 En este sentido, las revoluciones cientificas son rupturas de largas tradiciones de actividad profesional por parte de comunidades científicas. Lo que posibilita que estas tradiciones puedan tener lugar es un entramado instrumental y conceptual, un paradigma que aglutina a toda la comunidad científica en cuestión. Y es precisamente en la sustitución total o parcial de un paradigma por otro en lo que consiste precisamente la revolución (Espulgues Sanmartín, 1983: 141). 
problemas en la que se aplican unos mismos principios básicos, unas mismas concepciones ontológicas del objeto de estudio e investigación.

Según Diéz \& Moulines (1999: 443), en todo cambio intrateórico

existe una entidad estructural persistente a través del tiempo, un marco teórico [en el paradigma realista y modélico en el idealista, diríamos nosotros] que permanece invariable a pesar de los cambios y que es justamente el elemento sobre el que descansa la identidad de la teoría involucrada en el proceso [ciclo, precisaríamos nosotros], aquello que permite hablar de 'la teoría' en cuestión, teoría que sigue siendo la misma aunque se produzcan modificaciones más o menos significativas en ella.

La idea que presentan estos autores y que recoge la sostenida por Kühn (1981) y Lakatos (1974) entre otros, es que la teoría lingüística realista y el modelo lingüístico idealista, en sentido diacrónico, son una sucesión de teorias y modelos en sentido sincrónico que comparten un elemento común. Este elemento conforma la base ontológica constitutiva de los distintos programas de investigación lingüística que constituyen los diferentes ciclos epistémicos ${ }^{4}$.

El acercamiento lineal a partir del estudio dinámico pretende dar cuenta del segundo fenómeno histórico mencionado con anterioridad; esto es, el de la continuidad a través de la ruptura. Es lo que en Filosofía de la ciencia se conoce como cambio interteórico. La finalidad es la de poner en relación cada uno de los distintos momentos (de crisis, esplendor y transitorio) de los ciclos establecidos, con el fin de comprender en su justa medida la reelaboración lingüística evolutiva de los distintos programas de investigación y cómo se ha producido la misma.

Siguiendo a Díez \& Moulines (1999: 451 y ss.), podemos decir que existen dos grandes tipos de cambio interteórico; a saber, el de la incorporación de teorías sin inconmensurabilidad y el de la suplantación de teorias acompañada de inconmensurabilidad.

El primero de ellos - el cambio teórico y modélico como incorporación - representa un proceso evolutivo si tenemos en cuenta que los presupuestos de la teoría y el modelo que constituye los programas de investigación lingüística realista e idealista incorporadores son más amplios y lógicamente más fuertes que los de la teoría y el modelo de los programas de investigación incorporados ${ }^{5}$. Además, también el dominio de aplicaciones con éxito de los primeros abarca a los del segundo. Así, la investigación lingüística progresa por acumulación y su historia se convierte en consecuencia en una disciplina con dos funciones: relatar y registrar los incrementos sucesivos, por una parte, y describir y explicar, por otra, el conjunto de errores, mitos y supersticiones que impidieron una acumulación más rápida del caudal científico (Espulgues Sanmartín, 1983: 140). Estos procesos suelen ser siempre indicadores de una situación de crisis en el programa de investigación vigente, provocado por alguna anomalía grave (Polo, 1986: 121).

4 Para todo ello puede verse nuestro trabajo Jiménez Ruiz, 2004 - en prensa-.

5 La imagen clásica del proceso de investigación presenta la dinámica científica básicamente como un proceso de acumulación de teorías y modelos, algunos de los cuales se descartan por considerarse incorrectos. Desde el punto de vista del cambio como incorporación, lo que harían las nuevas teorias y modelos sería recoger los anteriores dentro de sí mismos, sin eliminarlos; como sostienen Zarco \& Cozar (2001: 54), explicarían lo mismo que los anteriores pero además otras cosas y de manera más profunda. 
El siguiente cambio - el de la suplantación de teorías y modelos - constituye la auténtica revolución Kuhniana, puesto que se produce una verdadera sustitución total de una teoría por otra en el caso del realismo y de un modelo por otro en el caso del idealismo, gracias al fenómeno de la inconmensurabilidad que se produce entre las teorías y los modelos ${ }^{6}$. Ello quiere decir que, en el caso de la Lingüística realista, se instaura un nuevo sistema de conceptos que invalida los de la teoría anterior considerándolos falsos y meros marcos categoriales; y que, en el caso de la Lingüística idealista, no hay forma de correlacionar semánticamente las categorías básicas de un modelo con las del otro y tampoco se puede establecer ninguna relación lógica entre los presupuestos de uno y otro modelo.

En ambos casos - tanto en el del cambio intrateórico como en el interteórico - estamos ante una concepción natural del progreso lingüístico, puesto que, incluso en el caso del cambio por suplantación, las teorías y modelos de los programas de investigación suplantadores explican las anomalías de las teorías y modelos de los programas suplantados.

Lo cierto es que estos cambios han posibilitado concepciones muy heterogéneas de nuestro objeto lingüístico que resulta ser considerado social o natural, empirico o trascendental, formal o conceptual, etc., según se ponga de relieve alguna de sus peculiaridades. Ello ha dado como fruto programas de investigación ${ }^{7}$ de diversa índole que constituyen los pilares de la historia de la Lingüística.

Ante estos hechos, creemos que el esfuerzo epistemológico debe consistir en señalar las diferentes bases ontológicas que se han atribuido al lenguaje, precisando en cada período de la historia aquellas que han sido determinantes - gracias a las oposiciones generadas- de programas de investigación lingüística importantes.

Y para ello, nada mejor que realizar el doble acercamiento señalado; a saber, el lineal - de los paradigmas realista e idealista - y el opositivo - a partir de los procesos cíclicos generados por las ontologías mencionadas-.

En este trabajo nos limitaremos al acercamiento lineal al Paradigma realista de la Lingüistica que, en este caso, a partir del estudio dinámico nos permitirá dar cuenta del fenómeno histórico de la continuidad a través de la ruptura. Como dijimos más arriba, se trata de poner en relación cada uno de los distintos programas de investigación de la Lingüística realista dentro de los diferentes ciclos epistémicos, con el fin de comprender en su justa medida el cambio interteórico, es decir la reelaboración lingüística evolutiva que se ha producido en los distintos programas de investigación y cómo se ha producido la misma.

\section{Los orígenes de los programas de investigación realista}

La tradición realista en la reflexión epistemológica sostiene en general que lo que se da en el conocimiento verdadero es algo real y objetivo, distinto e independiente del sujeto (Faerna, 1996: 270) Esta tradición representa una vertiente optimista. Los realistas no sólo piensan que en principio tenemos la capacidad de elaboración teórica sino que se ha ejercido

\footnotetext{
6 Es el caso de las ciencias experimentales que, lejos de desarrollarse por adición, lo hacen por selección. Pensemos, por ejemplo, en la física matemática que luchó contra la física aristotélica para demostrar que era falsa; cf. Arbaizar, 2001: 31 .
}

7 Como puede entenderse, estamos hablando todo el tiempo de «programa de investigación» en el sentido lakatosniano; cf. Lakatos, 1974: 28. 
con éxito esta capacidad a lo largo de la historia para lograr el progreso (Newton-Smith, 1987: 51).

Prueba de ello la tenemos en los origenes de esta reflexión que se remontan hasta Aristóteles (Robles Ortega, 1997: 33; Losee, 1991: 5-25), que busca los principios del ente y la comprensión de éste a partir de la justificación de los conocimientos (Lenk, 1988: 9). Se trata de elaborar una teoría de las causas y los principios frente al conocimiento común, limitado sólo a la intuición de los datos empíricos (Geymonat, 1985: 122).

Vamos a representar el ciclo en el que situamos este programa de investigación realista. En este gráfico y en los sucesivos presentamos en un cuadro de línea continua de mayor grosor el programa de investigación que estamos estudiando. En este caso, se trata del programa aristotélico, que constituye el germen de los distintos programas de investigación realista que se han dado a lo largo de la historia.

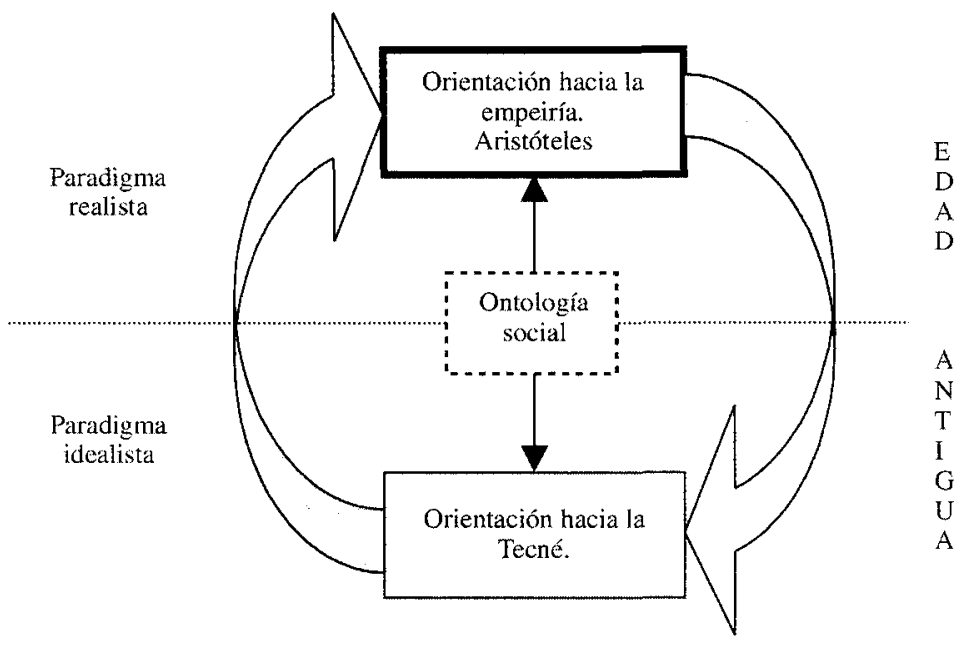

Así, la facultad humana de conocer - propia de la forma - se encamina a la comprensión de los seres reales y puesto que todo conocimiento comienza por la sensibilidad en los sentidos, lo único que se puede comprender en la realidad es su forma. Dicho de otra manera, el proceso del conocimiento debe consistir en la abstracción de la forma a partir de la materia para poder comprenderla (Monserrat, 1984: 16).

Ello quiere decir que para Aristóteles al principio está la observación y, como reconoce certeramente Mardones (1991: 21), la descripción —realista - sólo se conseguiría desde el punto de vista aristotélico cuando se pudiera dar razón de los hechos o fenómenos. Por tanto, son los hechos o fenómenos que se pretenden estudiar los que nos permiten en un primer momento la obtención de principios explicativos - inducción-y, en un segundo estadio, la elaboración de enunciados acerca de los fenómenos a partir de las premisas que contienen los principios explicativos - deducción-.

En este sentido, Aristóteles exigía una relación causal entre las premisas y las conclusiones. Se trataba de explicaciones teleológicas que aclaraban con qué finalidad ocurrían los fenómenos. 
Llevado al terreno lingüístico, este proceso cognoscitivo dio lugar a la teoría thesey, basada en la concepción regular del lenguaje a partir de una serie de reglas estrictas. Así entendido, el signo lingüístico no será una representación conceptual en el sentido de contenido mental sino un simple «deslindamiento de unidades» susceptible de variación y de empleo diversos de acuerdo con la estructura de cada lengua, cuyo funcionamiento hay que descubrir para poder conocerlo.

\section{El realismo epistemológico durante la Edad Media}

Esta reflexión será continuada por el Nominalismo medieval (Sto. Tomás, G. De Ockam), que propone una nueva teoría del conocimiento científico en la que el objetivo es ya lo particular y lo probable. En este sentido, se plantea la problemática del lenguaje desde el punto de vista lógico, aplicando la Lógica aristotélica a la Gramática puesto que ambas tienen un objeto en común: la oración significativa - aunque al gramático le interesa la oración concluida y al lógico la oración verdadera-.

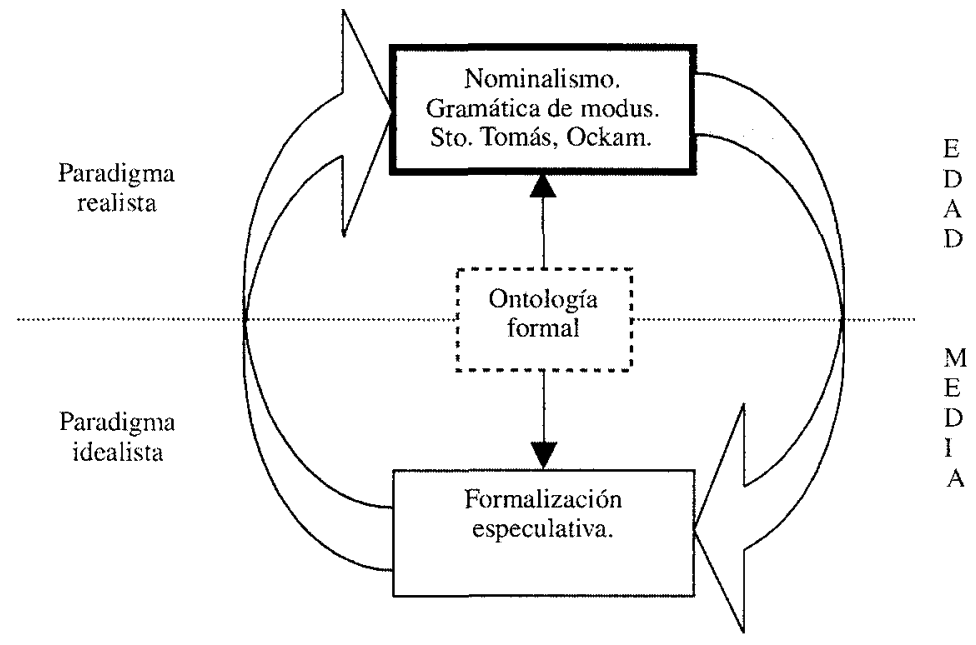

Así, piensan que la Lógica está subordinada a la Gramática y que ésta es anterior a toda lengua particular. Por ello, la Gramática será la ciencia del lenguaje y su ámbito de estudio el de la oración y el de los modificadores, teniendo por finalidad la expresión de los conceptos de la mente en oraciones bien formadas. Algunos de los principales modalistas fueron Petrus Heliae, Rogert Bacon, Thomas de Erfurt y Siger de Courtrai.

En este orden de cosas, frente a la sabiduría del pensamiento medievalista - que desarrolla la Metafísica aristotélica ocupándose de las causas y de los principios primeros-, la ciencia - en nuestro caso, la Gramática como ciencia del lenguaje - se ocupará de las causas inferiores - lo particular, específico y probable de cada lengua-. En este campo destacan los estudios de Bacon sobre la gramática hebrea, San Cirilo, arzobispo eslavo que estudia el eslavo eclesiástico y después la lengua eslava estándar o Dante con su De vulgari elocuentia. 


\section{Los programas de investigación realista durante la Modernidad}

La Modernidad - que va desde la caída de Constantinopla (1453) hasta la caída del Antiguo Régimen (1789) - se inicia con las gramáticas particulares durante el Renacimiento, continúa con las Gramáticas descriptivas del Empirismo y finaliza con las propuestas criticistas de finales del siglo Xvil.

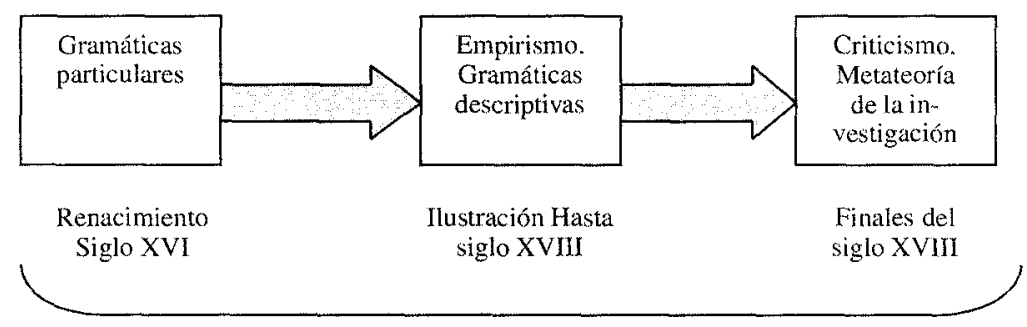

EDAD MODERNA

En este período se sostiene que el conocimiento es una actividad mental mediante la cual el hombre se apropia de algo del mundo exterior. Evidentemente, este modo de apropiación es, sin embargo, una forma peculiar de captar y aprehender el mundo exterior ya que éste permanece siempre intacto y lo que el hombre hace es simplemente representar intelectualmente un objeto (Jiménez Ruiz, 1994: 195).

Se produce, pues, una concepción del mundo fruto de una nueva forma de mirarlo, quizá más funcional y mecanicista que sustituye las preguntas sobre el "por qué" y el "para qué" por el "cómo" se producen los fenómenos y "cuáles" son sus consecuencias (Mardones, 1991: 24).

En el terreno lingüístico, esta actitud va a propiciar el estudio de las gramáticas vernáculas con influencia del mundo de la Filosofía (Locke, Hume) y de las Ciencias Naturales (Galileo, Newton).

\subsection{Las Gramáticas particulares del Renacimiento}

La Edad Moderna se inicia con el Humanismo (movimiento cultural, científico, filológico que desarrolla el Renacimiento) y presenta dos fechas y fenómenos históricos que influirán en el desarrollo de la Lingüística: 1453, en el que se produce el hundimiento del Imperio Bizantino; y 1492, en el que se descubre América. Nace, por tanto, la era de los descubrimientos. 


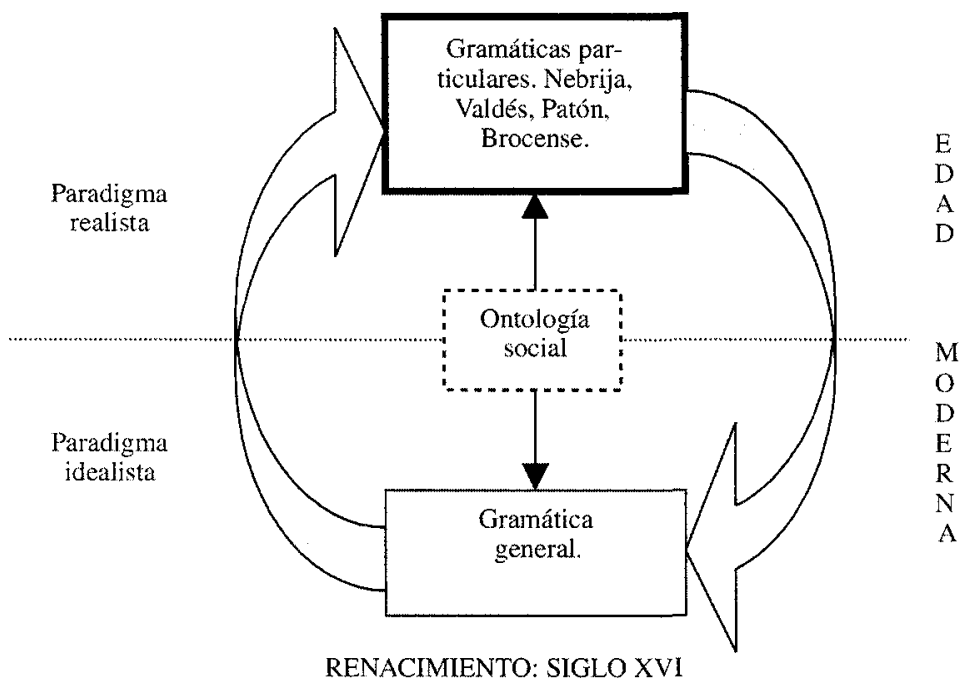

Como explicamos con anterioridad (Jiménez Ruiz, 2001: 127), estos acontencimientos influyen en lo siguiente:

En la nueva consideración de las lenguas antiguas (del latín, griego y más tarde del hebreo). Destaca Erasmo de Rotherdam que domina los tres. Su Elogio de la locura lo escribe en latín.

En la ampliación de la consideración de las lenguas vulgares europeas estudiadas hasta el siglo xvı. Se estudiará ahora el español (Gramática castellana de Nebrija, de 1492; Diálogo de la Lengua, de Juan de Valdés (1535), Instituciones de la Gramática española, de Ximénez. Patón, Minerva, de El Brocense), el italiano (Lorenzo el Magnífico) y otras lenguas como el inglés, polaco, eslavo, portugués, etc. Durante los siglos XVII y XVIH se estudiarán las lenguas extranjeras por la evangelización. En este sentido, juega un papel muy importante el trabajo de los jesuitas para el estudio de lenguas como el chino, japonés, tailandés, etc.

Ello justifica el amplio establecimiento de gramáticas particulares, centradas en su vertiente comunicativa principalmente.

\subsection{La investigación empirista}

En este sentido, será con el Empirismo (Bacon, Locke, Berkeley, Hume) cuando se vincule la Lingüística a las Gramáticas descriptivas —vernáculas-, como paso previo a las formulaciones estructuralistas, tanto europeas como americanas.

Los puntos fundamentales de esta Epistemología empirista son los siguientes (Monserrat, 1984: 18):

- La convicción de que el conocimiento tiene su origen en la experiencia y de que ésta se da sólo a través de sensaciones externas o internas.

- El hecho de que la conciencia en el conocimiento sólo constata lo dado en las sensaciones. 
- Y, finalmente, la certeza de que en la conciencia se forman las ideas de las cosas por asociación de las diferentes sensaciones ${ }^{8}$.

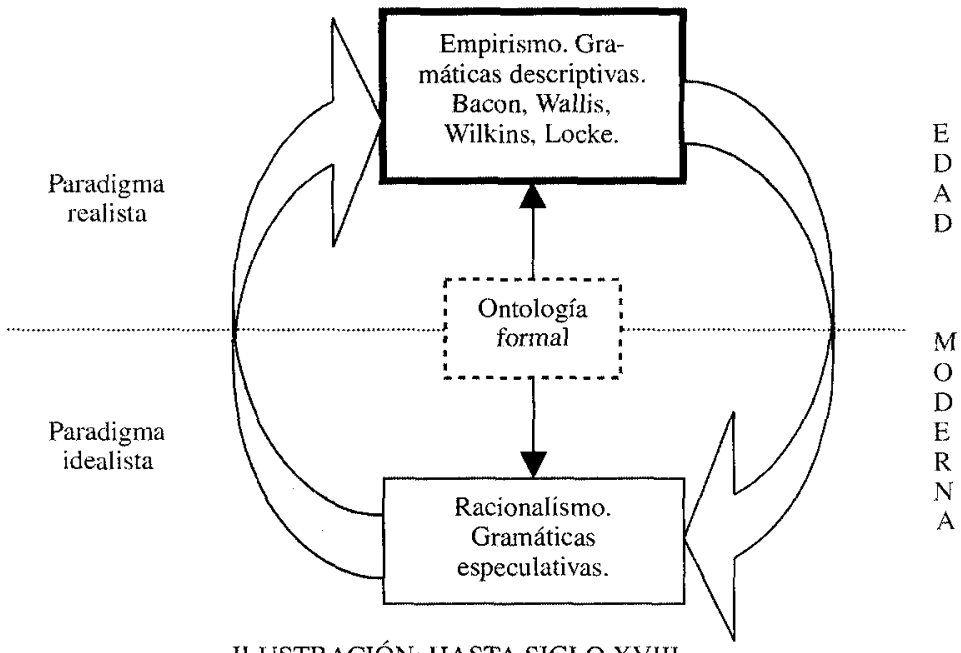

ILUSTRACIÓN: HASTA SIGLO XVIII

La Teoría del conocimiento empirista va a derivar en un concepto de inducción de importantes consecuencias. Puesto que por la inducción se procede a la generalización o formulación de la expectativa, fe o creencia de que un suceso se va a dar como acostumbra a constatarse, el conocimiento científico va a consistir en la generalización y ordenación de las expectativas cognitivas del hombre sobre la Naturalezay. En este sentido, esta nueva concepción cientificista recogerá un interés pragmático, acorde con el intento de dominar la Naturaleza, precisando, en palabras de Mardones (1991: 25), una auténtica actitud tecnológica del conocimiento, que rechaza las teorías, aceptando sólo la evidencia (Laudan, 1993: 65).

Así, autores como Bacon, Wallis, Wilkins, Locke, Berkeley y Hume reflexionarán sobre estas cuestiones (Jiménez Ruiz, 2001: 129-130).

F. Bacon en 1623 escribe su Sobre la dignidad y el proceso de la ciencia, en el que diferencia tres tipos de estudios del lenguaje:

-- La Granática literaria o descriptiva, que estudia las palabras y sus mutuas analogías.

- La Gramática filosófica o especulativa, que estudia la analogía entre las palabras y las cosas.

- La Gramática comparada, que estudia todas las lenguas con la idea utópica de llegar a la lengua perfecta. Esta idea continuará en el siglo XvilI.

John Wallis estudia la fonética inglesa en su obra Tratado gramático físico sobre la formación de sonidos, aplicando los presupuestos empiristas.

8 Precisamente, de estas observaciones surgen las teorias asociacionistas de Hume.

9 Así, por ejemplo, en el caso de Berkeley, parte del análisis del lenguaje empleado en la mecánica newtoniana para describir esta naturaleza, construyendo una Filosofia de la ciencia en la que estudia desde el problema de los significados de los términos hasta el estudio cognoscitivo de las teorías científicas; cf. Rioja, 1996: 145-165. 
Wilkins es un Obispo de la Iglesia anglicana que busca una lengua universal sin éxito en su obra Ensayo hacia un alfabeto universal y lenguaje filosófico, de 1668.

Finalmente, otra línea de investigación es la sostenida por Locke, quien realiza una semántica filosófica en su obra Ensayo sobre el conocimiento humano, reflexionando sobre los viejos problemas del lenguaje; esto es, la división entre palabra y cosa, sobre la que adopta la postura nominalista - las palabras sólo son nombres de las cosas -; la relación entre lenguaje y pensamiento, a los que considera realidades independientes; $y$, finalmente, la importancia del lenguaje, que es quien nos permite el conocimiento.

Sin embargo, y a pesar de lo que pudiera pensarse, no hay una auténtica Filosofía de la investigación en los empiristas británicos del siglo xvin, sino una Teoría crítica del conocimiento humano en general que, aunque tiene implicaciones para la Epistemología realista, sólo lo hace en temas comunes muy generales (percepción, causalidad, inducción) y en el cuestionamiento de toda forma de conocimiento humano (Díez \& Moulines, 1999: 28).

\subsection{La aportación criticista}

A finales del siglo xvin la Epistemología realista recibe un nuevo impulso con la Crítica de la Razón Pura y los Fundamentos Metafisicos de la Ciencia Natural de Kant, estableciendo una metateoría sistemática de las teorías científicas a partir de la geometría euclidea como teoría del espacio físico y la mecánica newtoniana como teoría del movimiento.

Partiendo de las propuestas de la física newtoniana, Kant busca la manera de explicar cómo es posible la determinación científica y el establecimiento por ella de verdades que invaliden el carácter científico de la metafísica ${ }^{10}$.



FINALES DEL SIGLO XVIII

10 Con todo, el desenvolvimiento del criticisno kantiano en dirección idealista abocó en la absolutización de la lógica trascendental como fundamento último de toda teoría cognoscitiva; cf. Muñoz \& Velarde, 2000: 206-207. 
Sus propuestas han jugado un papel muy importante en la Epistemología realista puesto que, aunque - como reconocen Díez y Moulines (1999: 28) - ya no sean aceptadas en su totalidad hoy en día, sí han tenido una gran repercusión en discusiones epistemológicas hasta bien entrado el siglo xx. Así:

marcó la pauta de la discusión de una serie de temas y conceptos que han jugado un papel central en la Filosofía de la Ciencia de la época contemporánea (relación teoría-experiencia; función de las matemáticas en la ciencia empírica; carácter de las regularidades nómicas; naturaleza de la causalidad, del espacio y del tiempo (Díez \& Moulines, 1999: 29).

Se instaurará, pues, un nuevo orden que tomará como modelo las Ciencias físicas y que sentará las bases de lo que será la revolución positivista posterior:

la liberación de la filosofía, representada por la metafísica y la lógica; la atención a los hechos, con el consiguiente destierro de todo subjetivismo y apriorismo filosófico o teológico; y la búsqueda en estos hechos de leyes matemáticas (Martí Sánchez, 1998: 40).

\section{La Epistemología realista como investigación inmanente del conocimiento}

La Epistemología realista será entendida posteriormente - durante la Edad Contemporánea- como una epistemología centrada en la investigación inmanente del conocimiento científico; en este sentido, la cientificidad ya no residirá en el objeto, en lo universal, sino en el método (Estany, 1993: 66). Esta epistemología será la realizada concretamente por el Positivismo de Comte en la primera mitad del siglo xix, la Lógica moderna, establecida por Frege a finales del xIx y consolidada por Russell y Wittgenstein a principios del xx, el Empirismo lógico de Carnap y el Círculo de Viena (Schilick, Neurath) hasta finales de la $2^{\mathrm{a}}$ Guerra Mundial, y finalmente, la Filosofia del la Ciencia de Popper, Hempel, Feigl y Goodman.

\section{INVESTIGACIÓN INMANENTE DEL CONOCIMIENTO}

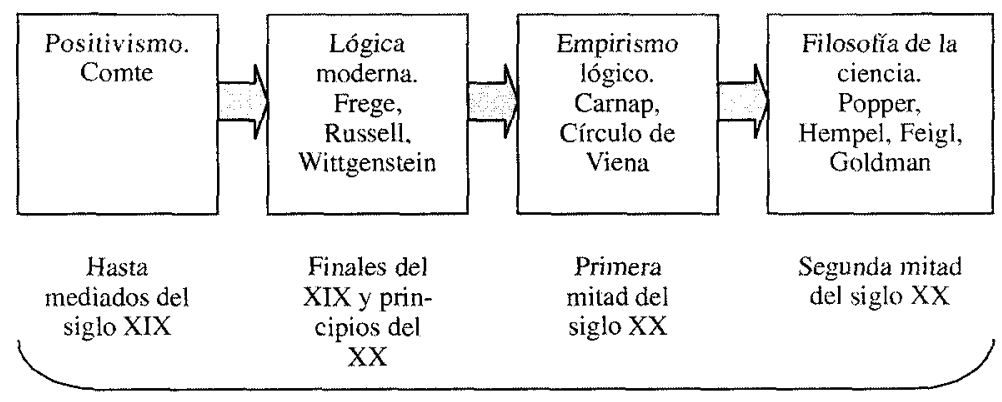

EDAD CONTEMPORÁNEA

Sin embargo, será precisamente con el Círculo de Viena con el que la Epistemología se constituirá como una disciplina diferente a otras ramas de la Filosofía. Lo hará con una serie de investigadores procedentes de distintos ámbitos del saber que se organizarán alrededor de 
la cátedra de Filosofía de las Ciencias inductivas que Schilick había obtenido en 1922, con el objetivo de localizar las teorías calificadas como científicas - sobre todo en los libros de textos usados en las universidades - y reconstruirlos para poner al descubierto e identificar el sistema axiomático formal subyacente a cada una de ellas (Valor Yébenes, 2000: 18).

Veamos, aunque sea brevemente, algunos de estos estudios inmanentistas.

\subsection{El programa de investigación positivista}

Los epistemólogos de la primera mitad del siglo XIX serán principalmente científicos y matemáticos, y filósofos sin preparación científica. Por ello, uno de los conceptos fundamentales de este periodo es el de ley cientifica, precedido por los de principio y ley de la Naturaleza (Echeverría, 1993: 68 y ss.). Entre estos pensadores podemos destacar, como ya hemos mencionado, a Comte, el fundador del Positivismo.

PRIMERA MITAD DEL SIGLO XIX

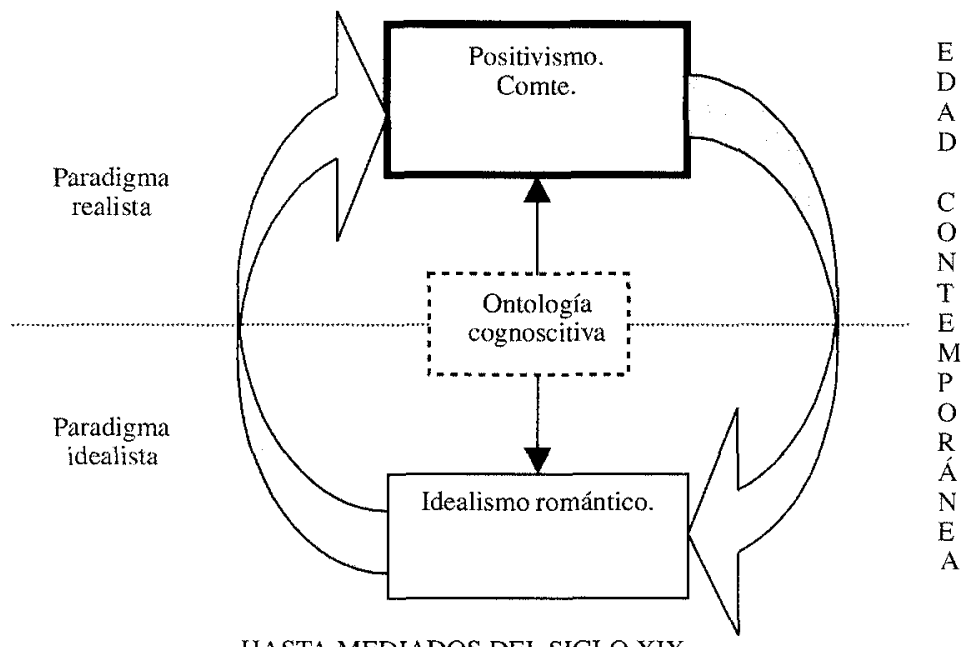

HASTA MEDIADOS DEL SIGLO XIX

Comte defendía el proyecto de una ciencia unificada que exigía la construcción de una Teoría de la ciencia que fuese ella misma científica, apartándose de la Wissenschaftstheorie de talante metafísico imperante desde el siglo XIX (Valor Yébenes, 2000: 17).

Esta Teoría de la ciencia se basará en los siguientes puntos (Mardones, 1991: 29):

1) El monismo metodológico, que implica una única manera de entender lo que se considere una auténtica explicación científica.

2) El modelo de las ciencias naturales exactas, que se constituyen en el auténtico ideal metodológico frente al que se confronta la perfección del resto de las ciencias.

3) La explicación causal como característica de la explicación científica, puesto que las ciencias tratan de responder a la pregunta del «por qué» ha sucedido un hecho.

4) El interés dominador del conocimiento positivista, centrado en el control y dominio de la Naturaleza. 
Por tanto, Comte presenta un enfoque descriptivo, puesto que trata de mostrar la totalidad de las disciplinas establecidas en su tiempo en un esquema jerárquico general, tanto sincrónica como diacrónicamente (Díez \& Moulines, 1999: 29).

Todas estas disciplinas científicas no tendrán más obligación que la de la observación directa de los hechos empíricos con objeto de descubrir las leyes universales que los rigen - de carácter matemático y no metafísico--, y poder conocerlos".

En palabras de Comte, podemos decir que:

En las leyes de los fenómenos [el subrayado es nuestro] es en lo que consiste realmente la ciencia, a la cual los hechos propiamente dichos, por exactos y numerosos que puedan ser, nunca procuran otra cosa que materiales indispensables (Comte, 2000:31).

\subsection{La importancia de los planteamientos lógicos}

A finales de finales del siglo xIx y principios del xx la Epistemología seguirá siendo una parte de la Teoría del conocimiento o Gnoseología, que estudia la naturaleza del conocimiento científico en oposición al vulgar, la clasificación de las distintas ciencias y la posibilidad de construir una ciencia a partir de la observación (Bunge, 1980: 14), con objeto de elevar a categoría de ciencia los fundamentos de los distintos saberes parciales que expliquen la realidad y justifiquen su existencia.



FINALES DEL XIX Y PRINCIPIOS DEL XX

En este sentido, los planteamientos kantianos -más que los positivistas - tienen su influencia en una serie de enfoques metateóricos que, aunque críticos con Kant, retoman sus preocupaciones por establecer la estructura del conocimiento científico. Entre estos enfoques, Díez \& Moulines (1999: 29) citan los siguientes: el Pseudokantismo empirista de

11 De hecho, para Comte, el conocimiento tiene como único objeto el fenómeno; cf. Monserrat, 1984: 46. 
Helmholtz, el Instrumentalismo de Duhem, el Pragmatismo de Peirce ${ }^{12}$ o el Empiriocriticismo de March $^{13}$.

Junto a este conjunto de enfoques de inspiración kantiana, otro de los grandes pilares de la Epistemología realista de finales del XIX y principios del xx lo constituye la Lógica moderna, establecida por Frege, consolidada por Russell a principios del xx, y continuada posteriormente por Wittgenstein.

Característico de esta tendencia, enmarcada dentro de lo que se denomina Filosofia analítica, sería la consideración de que sólo los enunciados sometidos a la lógica y a la verificación empírica pueden ser considerados como científicos (Mardones, 1991: 33). En este sentido, la gran aportación de Russell a la Epistemología realista del siglo xx ha sido la elaboración de la primera gran síntesis doctrinal perfectamente estructurada de la lógica formal (Monserrat, 1984: 52). A partir de la concepción referencialista del significado de Frege (1971), quien distingue el sentido de un signo de la referencia -objeto al que el signo alude- y sostiene que el sentido es el enfoque bajo el que se contempla el objeto, establece que el lenguaje estaría constituido por proposiciones moleculares, compuestas de proposiciones atómicas, que serían los elementos básicos del lenguaje; y por proposiciones atómicas, formadas por nombres propios que tienen carácter de índice, de alusión deíctica al mundo del referente (Meix Izquierdo, 1982: 36-38).

Como puede apreciarse, vemos su propuesta realista en el reconocimiento de la existencia del mundo del objeto al margen de la presencia de cualquier sujeto cognoscente. Por ello, el lenguaje ideal será el que refleje estructuralmente la realidad. Sin embargo, de acuerdo con su orientación empirista, debe aludir a vivencias directamente vividas por el sujeto.

Este proceso, según Russell (1949: 48), sigue tres etapas:

La primera consiste en observar los hechos significativos; la segunda, en sentar hipótesis que, si son verdaderas, expliquen aquellos hechos; la tercera, en deducir de estas hipótesis consecuencias que puedan ser puestas a prueba por la observación.

Posteriormente, Wittgenstein parte de la identificación y reconocimiento de los hechos como constitutivos fundamentales del mundo, pues ambos tienen los mismos límites. Los nombres significan el objeto al que se refieren pero no son simples reflejos de dicho referente; tienen una estructura lógica representada en la proposición (pasándose de una concepción denotacional del significado a una más amplia, adjudicando a la proposición el sentido en el conjunto de la frase). Por tanto, la proposición tiene un carácter componencial que pretende dar un nuevo sentido con expresiones viejas. Surge, entonces, la teoría del mostrar: la función más importante de la proposición es darnos a conocer la estructura de lo real.

En este sentido, los nombres de las cosas no nacen del análisis de los fenómenos sino de la aplicación de una palabra en un lenguaje que se ha aprendido en la vida. Así, analizamos conceptos y, por tanto, aplicaciones de palabras (Wittgenstein, 1988: 379 y ss.) a través de

12 Un interesante trabajo en el que se ponen en relación los presupuestos teóricos de Peirce con los de Frege sobre el signo lo constituye el estudio de Rivas Monroy (1996: 1211-1224).

13 Quizá la aportación más importante sea la crítica realizada por March de las categorías de sustancia y causalidad, sin las cuales no hay ensayos metafísicos, y su sustitución por una ley constante de relaciones entre los fenómenos. Por tanto, en la realidad del momento la existencia de la ciencia se justifica por el descubrimiento y la valoración de los fenómenos. 
un «juego lingüístico» que exige la construcción de una epistemología que, en el fondo acabó siendo artificial, y acentuó la separación entre lo científico y lo filosófico.

\subsection{El giro lingüístico del Empirismo lógico}

A partir de la $1^{a}$ Guerra Mundial se acentúa la oposición a la especulación metafísica sosteniéndose que ésta ha surgido debido a la relativamente ilimitada libertad lingüística de que gozan los hablantes de las lenguas naturales. Por ello, se pretende buscar un medio de control de esa libertad, eliminando así la especulación. Surge, por ello, una nueva Epistemología realista que será llamada Empirismo lógico o Positivismo lógico.

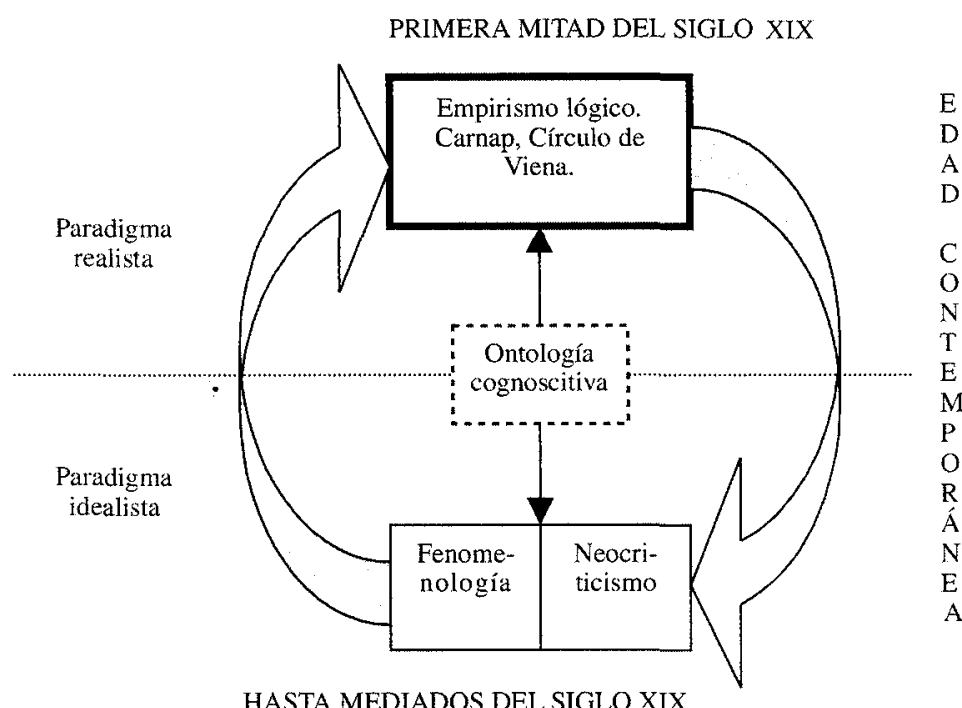

Basándose tanto en los contenidos de los temas y planteamientos de los físicos y filósofos de los enfoques metateóricos anteriores como en los métodos de la Lógica moderna, los epistemólogos realistas de este período establecen los que serán los temas principales de la Filosofía de la investigación científica y el modo de abordarlos.

La característica fundamental de esta nueva Epistemología es el giro lingüístico que se produce en ella con objeto de tratar los problemas epistemológicos a partir del examen de la forma en que éstos están encarnados en el lenguaje ${ }^{14}$. Para ello, tratan de elaborar un sistema constitucional de los conceptos (Monserrat, 1984: 66).

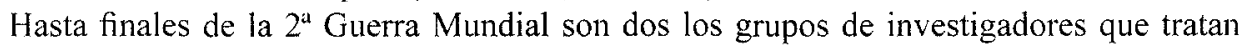
estas cuestiones, según Díez \& Moulines (1999: 30): el Grupo de Berlin, con Reichenbach al frente, y el Círculo de Viena, en el que destaca la figura de Carnap.

14 Efectivamente, la característica más importante de la filosofia del siglo xx es lo que se ha dado en llamar giro lingüístico; esto es, la conciencia de que nuestra relación con el mundo se articula lingüisticamente. Como sostiene Arbaizar (2001: 40), los seres humanos vivimos materialmente en un mismo planeta pero culturalmente en muchos mundos, lo que equivale a decir que se hacen diferentes lecturas de la vida en distintas claves lingüisticas. 
El Empirismo lógico, con Carnap al frente, trata de construir lenguajes artificiales con el rigor suficiente para impedir en ellos la expresión de la metafísica. Persigue así, como reconoce Mardones (1991: 33), el ideal de un lenguaje científico universal hecho de signos y símbolos nuevos, neutrales, unívocos, sin lastres históricos.

En este sentido, estudia la relación entre las entidades lingüísticas y las cosas de la realidad a las que tales entidades designan, y la relación entre las oraciones y las condiciones reales que deben reunir para que las oraciones sean verdaderas.

Así, la comprobación y verificación empírica de todas las oraciones tendrá por verdadero lo que expresa un estado de cosas objetivo. Para ello distingue entre:

1) Reglas de designación: las que dan una interpretación de los símbolos descriptivos en forma de designados específicos.

2) Y reglas de verdad: las que señalan las condiciones de verdad para las frases atómicas y un medio de encontrar las condiciones de verdad para una oración compuesta en términos de la verdad para sus oraciones atómicas componentes ${ }^{15}$.

Así entendida, la Epistemología estudiará las estructuras lógicas de las explicaciones junto con estrategias de seguridad, posibilidades de justificación y garantías de aceptabilidad de teorías (Lenk, 1988: 17) que, para él, tendrán un carácter representacional ${ }^{16}$. Como reconoce Álvarez (1988: 18 y ss.), en el fondo no se trata tanto de descubrir la realidad, sino de ser científicos.

\subsection{La Filosofía de la Ciencia}

El empirismo lógico tuvo un importante desarrollo y una gran influencia hasta la década de los 60 (Valor Yébenes, 2000: 18), a pesar de la crítica que Popper venía haciendo desde la publicación en 1934 de su Lógica de la investigación científica ${ }^{17}$.

Popper inaugura el que podríamos llamar período clásico de la Epistemología realista, en el que, a partir de la $2^{\mathrm{a}}$ Guerra Mundial, elabora una auténtica revolución epistemológica (Rivadulla, 1995: 7-33) a partir de la crítica a la opinión común de cómo los científicos usan el método inductivo para ampliar el conocimiento, proponiendo el abandono de la búsqueda de una verdad que escape a toda crítica (Medawar, 1993: 109). En este sentido, defiende el principio de falsabilidad, de cómo la búsqueda de la verdad que caracteriza la ciencia es una búsqueda sin término, un saber conjetural (Popper, 1977: 38). Por ello, como explica Mardones (1991: 37), la ciencia popperiana deja de seguir un camino inductivo para ser deductivo, abandonando el criterio de verificación para seguir el de falsificación.

15 Sin embargo, este tratamiento presenta insuficiencias. Su crítica se debe a Frege, (1971: 49-84), quien señaló que significación (Sinn) y designación (Bedeutung) son diferentes y que las construcciones no sinónimas pueden referirse a la misma cosa.

Las críticas de Frege y Quine obligaron a Carnap a volver de la semántica a la pragmática a fin de justificar los postulados significativos y las reglas semánticas en un lenguaje artificial; cf sobre la dialéctica entre las propuestas teóricas de Carnap y Frege, Kutschera, 1979: 60-75.

16 Efectivamente, la naturaleza representacional de las teorías científicas fue fijada en el sistema constructivo desarrollado por Carnap, por lo que puede ser considerado un precedente del punto de vista semántico; cf. al respecto Bengoetxea \& Eizaguirre, 1996: 31-45.

17 Se trata de una obra en la que Popper analiza las reglas del juego de la obtención de las hipótesis y teorías científicas. 


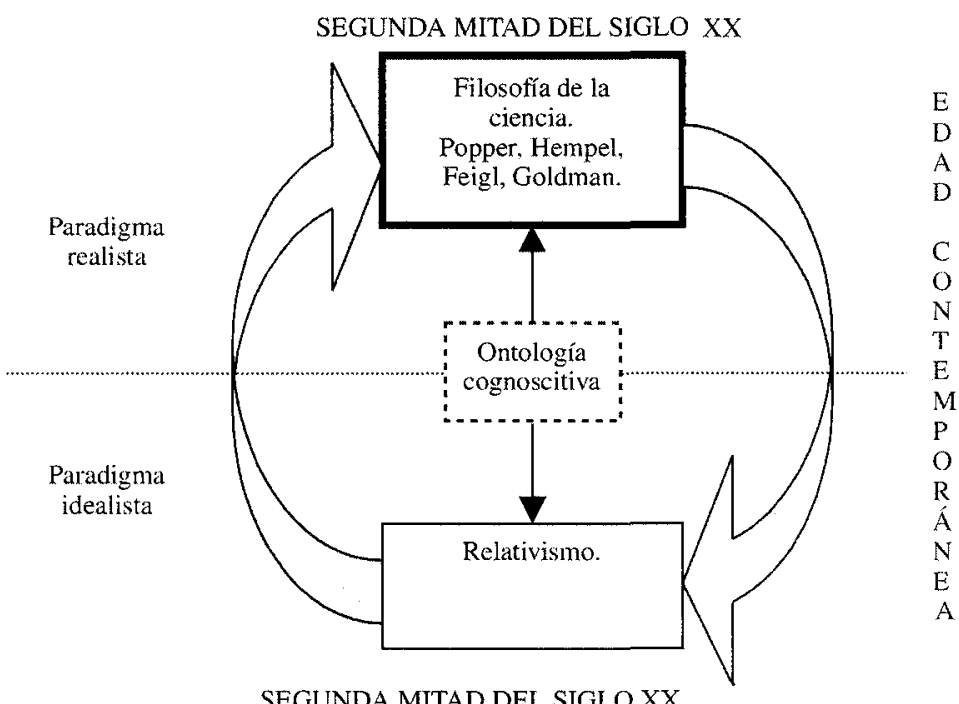

En palabras de Popper (1977: 262):

La ciencia nunca persigue la ilusoria meta de que sus respuestas sean definitivas, ni siquiera probables; antes bien, su avance se encamina hacia una finalidad infinita $-\mathrm{y}$, sin embargo, alcanzable-: la de descubrir incesantemente problemas nuevos, más profundos y más generales, y de sujetar nuestras respuestas (siempre provisionales) a contrastaciones constantemente renovadas y cada vez más rigurosas.

Por ello, hasta su muerte en 1994, rechaza la concepción estética de la filosofía, que no intenta aclarar ni analizar los conceptos ni expresar el espíritu de una época, sino elaborar teorias verdaderas sobre el conocimiento (Popper, 1994: 223 y ss.), sosteniendo que hay que tener en cuenta la práctica ${ }^{18}$ en un proceso de conocimiento acumulativo (Medina, 1989: 34 y ss.) que mida las teorías según su rendimiento, siendo la teoría mejor — no la verdadera-- aquella que tiene mayor grado de corroboración en sus intentos (Lenk, 1988: 22).

Su concepción de la epistemología es, por tanto, científica, desde el momento en que no puede separarse de ella ${ }^{19}$. Es una indagación crítica de la ciencia, una metodología básica para la corroboración crítica.

Por su parte, Hempel (1975: 100-144) desarrolla el esquema lógico popperiano de explicación causal, aplicando el modelo deductivo a la historia para sostener que existen leyes de implicación universal que enuncian la correlación regular de los fenómenos.

18 Es quizá el carácter sociológico de la teoria de Popper el que subyace aquí, al situar la esfera empirista en el ámbito social; cf. al respecto el planteamiento expuesto por Bunge, 2000: 169 y ss.

19 Para Popper, desde un punto de vista histórico, toda la investigación occidental es un derivado de la especulación filosófica griega acerea del cosmos, el orden del mundo, etc.; cf. Popper, 1994: 237. 
Para Bunge (1980: 14-22), tanto las propuestas de Carnap como las de Popper, al estar tan atadas al empirismo, no lograron dar cuenta de que las teorías científicas son cualquier cosa menos síntesis de datos empíricos.

\section{La Epistemología realista como investigación inmanente del lenguaje}

Este inmanentismo cognoscitivo tiene además —durante la contemporaneidad - su traducción al ámbito lingüístico en lo que será ya propiamente la Epistemología centrada en la investigación inmanentista - pragmática, funcional, operativa- del lenguaje (Jiménez Ruiz, 1994: 196). Ésta tendrá, por tanto, su desarrollo lingüístico en la Lingüística histórico-comparada (parangón del positivismo clásico anterior), su continuación neogramatical, el conductismo Skinneriano y el estructuralismo, ya sea en su vertiente americana, con Bloomfield, o europea, con Saussure y su desarrollo neopositivista posterior.

INVESTIGACIÓN INMANENTE DEL LENGUAJE

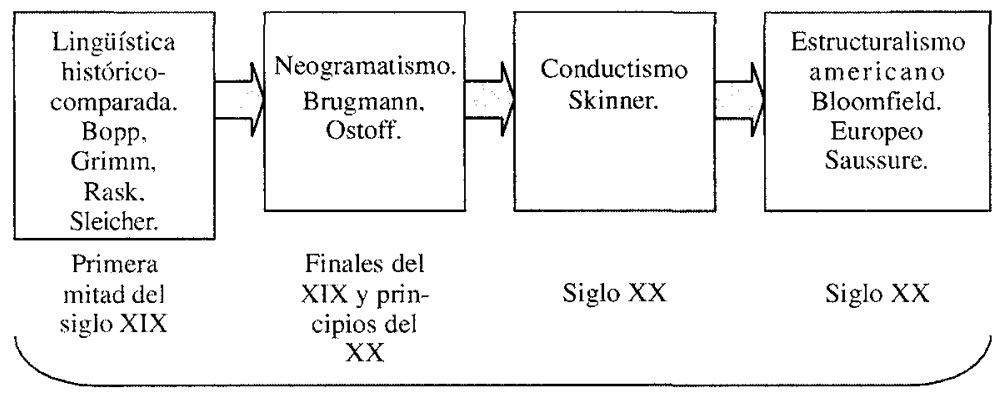

EDAD CONTEMPORÁNEA

\subsection{La exigencia cientificista de la contemporaneidad}

El positivismo, con su defensa del proyecto de la elaboración de una ciencia unificada que exigía la construcción de una teoría de la ciencia que fuese ella misma científica, favoreció en el ámbito lingüístico una auténtica revolución que inicia la base de los fundamentos para que la Lingüística pueda constituirse en ciencia, satisfaciendo de esta manera los presupuestos que exigía la contemporaneidad.

Así, la Lingüística histórico-comparada del siglo xIx (Bopp, Grimm, Rask, Schleicher) constituye el germen de esta cientificidad. Aunque, en cierto modo determinada por la ideología romántica (Kristeva, 1988: 196 y ss.), va separándose de ella, nutriéndose de la filosofía de Comte y de los avances de otras ciencias (Ortega, 1982: 135). Fruto de ello es el uso de términos como análisis, árbol genealógico, articulación, raíz, substrato, ondas, etc.

Como señala Martí Sánchez (1998: 46-50), el cientificismo de esta Lingüística históricocomparada se manifestará en el gran desarrollo que sufre la fonética, elaborando las distintas leyes que otorgan a la Lingüística el rango de Historia natural demostrada con evidencia 
matemática. Para ello, estas leyes fonéticas explican el cambio lingüístico contrastando la «regularidad en el interior de un grupo de determinados fenómenos históricos» (Arens, 1976: 471).



PRIMERA MITAD DEL SIGLO XIX

\subsection{La Lingüística como ciencia histórica positivista}

En el último tercio del siglo xix el método de la Gramática histórica experimentará un giro importante, transformándose la Lingüística en una ciencia histórica positivista, que fue denominada por los italianos Neogramática.

Los iniciadores del movimiento fueron Brugmann (1849-1919) y Osthoff (1847-1909), quienes sentaron las bases principales del grupo, que ya comentamos en otro trabajo (Jiménez Ruiz, 2001: 136); a saber:

- La fe ciega en las leyes fonéticas para explicar los cambios lingüísticos.

- La concepción mecanicista de la evolución del lenguaje.

- El carácter de ciencia histórica que recibe la Lingüistica.

- La consideración el individuo hablante como elemento fundamental del estudio lingüístico.

- El recurso consciente y sistemático a la psicología, pues consideran la psicología del hablante como un factor más en las causas del cambio fonético. 
FINES DEL XIX Y PRINCIPIOS DEL XX

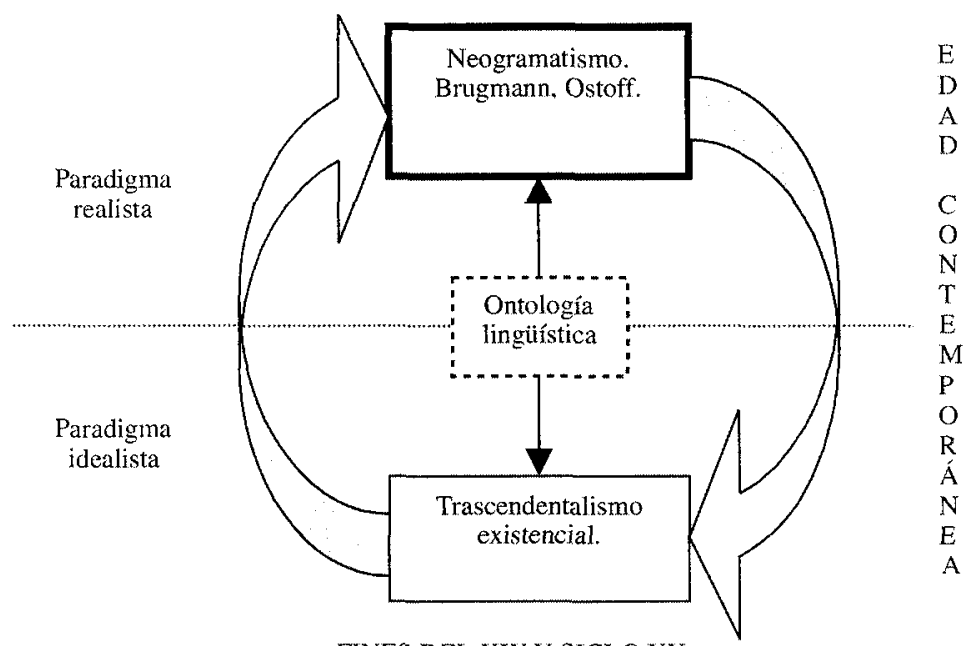

FINES DEL XIX Y SIGLO XX

\subsection{La importancia del uso lingüístico}

Por otro lado, las teorías conductistas parten de considerar el hecho de hablar como un comportamiento humano inserto en el conjunto total de la vida, y cuya función debe ser analizada en este ámbito partiendo del uso lingüístico, que se convierte, de esta manera, en el punto de partida hacia una investigación científica del lenguaje y, en última instancia, de la determinación del significado a partir de él (Kutschera, 1979: 81-83).

Llevado al terreno epistemológico, la teoría de Skinner se caracteriza por realizar una aplicación fundamental del paradigma del condicionamiento operante a la investigación de la conducta verbal ${ }^{20}$. Ello se traduce en un tratamiento causal o funcional satisfactorio de la conducta y, dentro de ésta, del comportamiento verbal. Por ello, establece relaciones causales entre el sujeto y los objetos. El sujeto se concibe como un mecanismo de aprendizajes complejos que pueden ser renovados por nuevas asociaciones. Lo interior es rechazado; de ahí que explique la relación sujeto-objeto mediante reflejos establecidos de antemano por condicionamientos y rechace las ideas mentalistas ya que tales posiciones habrían llevado a postular la existencia de lo lingüístico al margen de la conducta. Para llevar a cabo este análisis precisa que la unidad básica del mismo es el operante (encadenamiento de tres términos básicos: estímulo, respuesta y refuerzo).

Skinner, por tanto, trata lo verbal como respuesta y no como estímulo, y llega a la conclusión de que no existe relación correcta entre cada estímulo y su correspondiente respuesta verbal. La asociación correcta la marca la sociedad reforzante y la fuerza asociativa crece o decrece de acuerdo con las contingencias reforzantes. Podemos decir que a Skinner le 
interesan no los aspectos de mera traducción significativa de las palabras, sino tratamientos posteriores de éstas: sus agrupamientos. Y no los aspectos más sintácticos de los agrupamientos, sino sus aspectos funcionales. Por tanto, el comportamiento verbal se establece porque depende de acontecimientos externos reforzantes que lo controlan (Skinner, 1981).

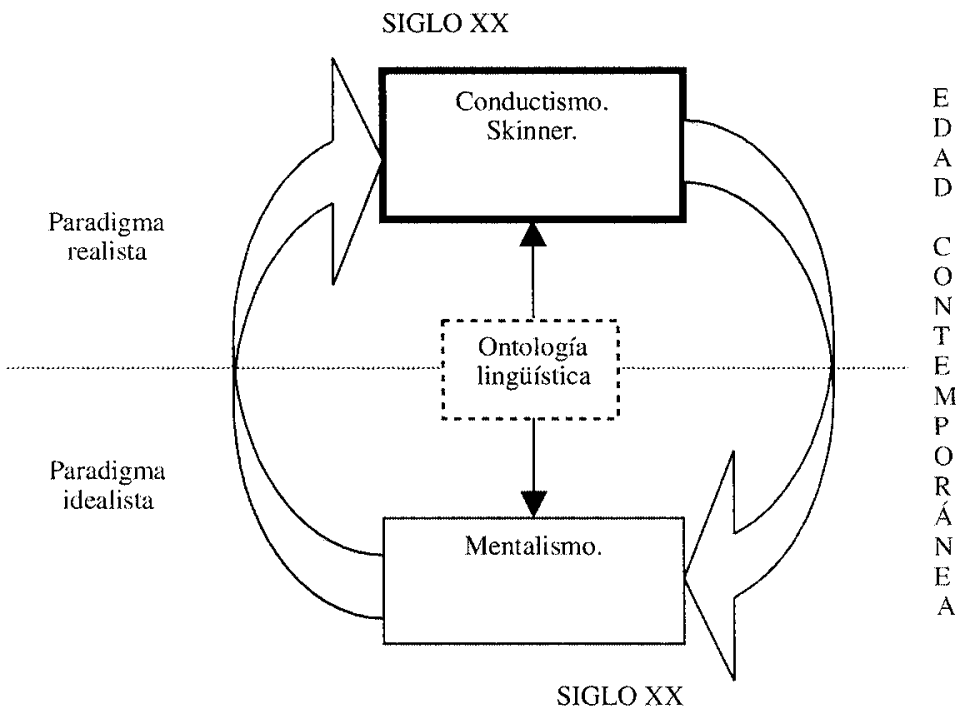

\subsection{EI Estructuralismo como prototipo del Paradigma realista de la Lingüística}

Para Bloomfield, hay que rechazar los antiguos trabajos lingüisticos de carácter descriptivo porque están plagados de nociones filosóficas - consideradas un estorbo-- ya que la exactitud de un estudio estará en la adecuación a los datos observados en la conducta de los hablantes (Bloomfield, 1964: 20-22). Por tanto, las úmicas generalizaciones útiles sobre la lengua serán las carentes de especulación.

Ello responde, obviamente, como reconoce Coseriu (1973: 138 y ss.), a la influencia del neopositivismo lógico. En este sentido, para Bloomfield (1964: 138), la ciencia tiene que ser descriptiva y esta descripción debe ser del objeto físicamente comprobable - en nuestro caso, de los enunciados considerados como cosas- y debe realizarse de manera interna, para no correr el riesgo de recurrir a hechos no científicos, que no son comprobables físicamente. De hecho, sostiene que es imposible hacer referencia a hechos no físicos - como, por ejemplo, la mente-- cuando se están estudiando hechos físicos de conducta --como es el lenguaje--.

Así, la ciencia sólo se ocupará de los hechos accesibles en su momento y lugar a todos y a cada uno de los observadores, hechos localizados mediante las coordenadas espaciotemporales (Bloomfield, 1964: 34).

Por ello, el proceso cognoscitivo pasa principalmente por el acopio de datos y la observación. Hasta tal punto es tan fuerte la insistencia en los datos y en la observación para la elaboración de un sistema teórico que, como reconoce Fernández Pérez (1984: 132), se ha calificado la propuesta de Bloomfield como empirista. 


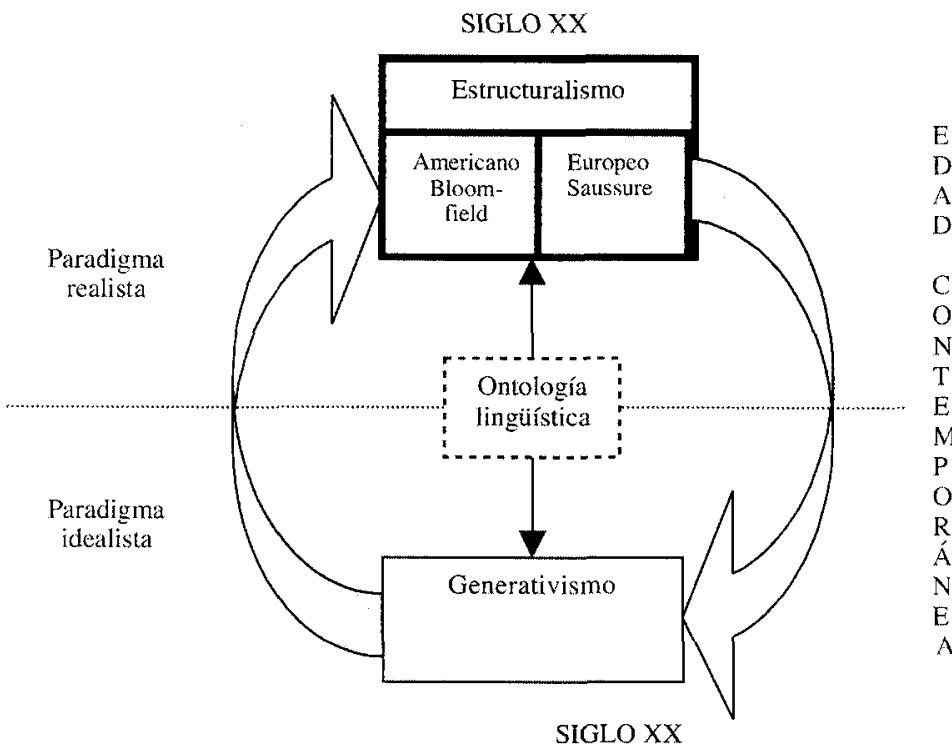

Sin embargo, es el Estructuralismo europeo de Saussure el que constituye el auténtico prototipo del Paradigma realista de la Lingüística, en un intento de construir teorías que no sean entendidas como unidades aisladas, sino de manera interrelacionada en el conjunto de red de teorías (Moulines, 1982) que constituyen el corpus de la ciencia lingüística. Por ello, vamos a concluir este breve panorama histórico representando ahora en un gráfico la evolución del Paradigma realista tanto en el ámbito estadounidense (columna de la izquierda), como en el europeo (columna de la derecha).

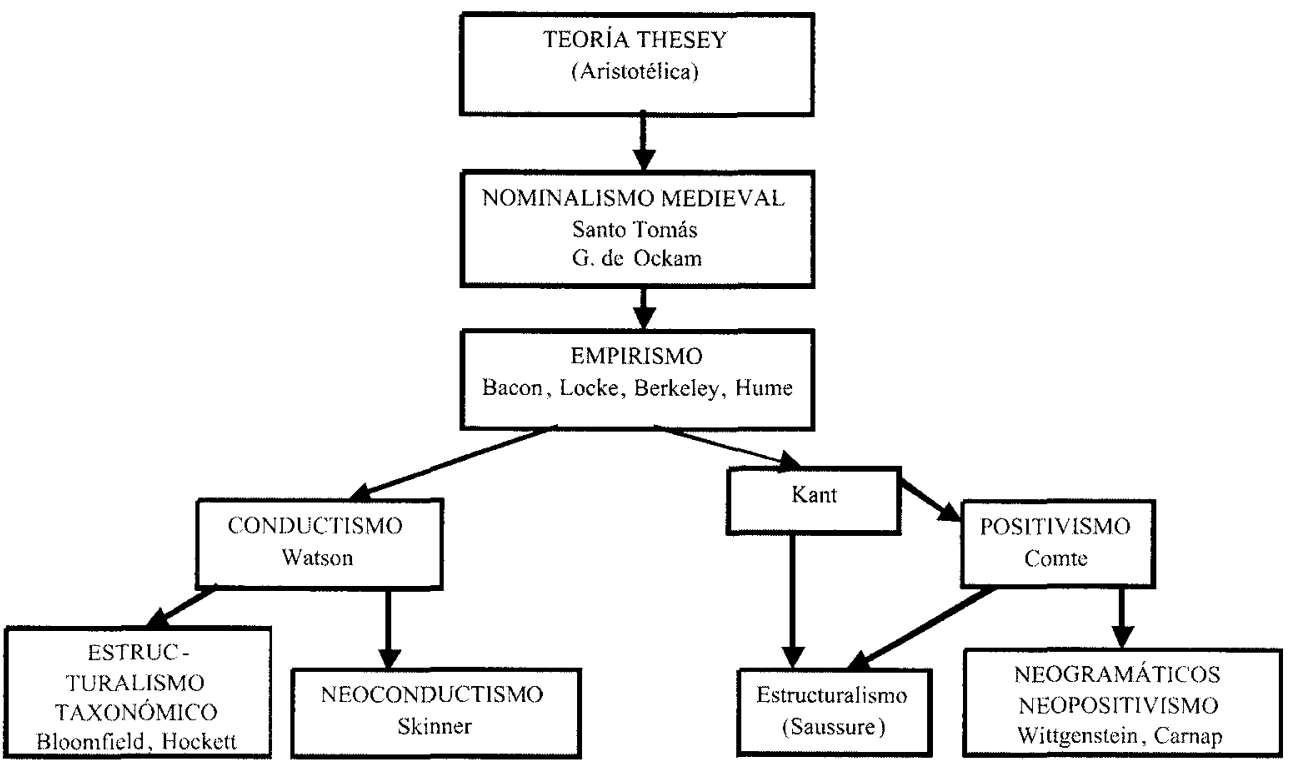




\section{Referencias bibliográficas}

AA. VV. (2001): Lecturas para estrenarse en Filosofía de la ciencia. Valencia, Diálogo, S. L. Álvarez, J. R. (1988): Ensayos metodológicos. León, Universidad de León. Arbaizar Gil, B. (2001): "Cartografia de las ciencias" apud AA. VV. (2001): 27-44.

Arens, H. (1976): La Lingüistica. Sus textos y su evolución desde la antigüedad hasta nuestros días, I y II. Madrid, Gredos.

Bengoetxea, J. B. \& Eizaguirre, X. (1996): "Carnap como antecedente del enfoque representacional de las teorías científicas", Arbor, 612, págs. 31-45.

Bloomfield, L. (1964): Lenguaje. Perú, Universidad Nacional de San Marcos.

Bunge, M. (1980): Epistemologia. Barcelona, Ariel.

Bunge, M. (2000): La relación entre la Sociología y la Filosofia. Madrid, Edaf.

Comte, A. (2000): Discurso sobre el espiritu positivo. Madrid, Alianza.

Coseriu, E. (1973): Teoría del lenguaje y Lingüistica General. Madrid, Gredos.

Díez, J. A. \& Moulines, C. U. (1999): Fundamentos de Filosofia de la Ciencia. Barcelona, Ariel.

Echeverria, J. (1993): "El concepto de ley científica", apud Moulines, C. U. (1993): 57-88.

Espulgues Sanmartín, J. (1983): Filosofia de la ciencia. Valencia, Episteme.

Estany, A. (1993): Introducción a la Filosofía de la ciencia. Barcelona, Crítica.

Faerna, A. M. (1996): Introducción a la teoría pragmatista del conocimiento. Madrid, Siglo XXI.

Fernández Pérez, M. (1984): "El carácter de la ciencia lingüística", Verba, 11, págs. 129-156.

Frege, G. (1971): Estudios sobre semántica. Barcelona, Ariel.

Geymonat, L. (1985): Historia de la Filosofia y de la Ciencia, I. Barcelona, Crítica.

González de Oleaga, $\mathrm{M}^{a}$ L. (1996): "De lobos y de fauces: el conocimiento sociohistórico en el fin de siglo", Revista de Indias, 56, págs. 475-501.

Hempel, C. G. (1975): "La explicación en la ciencia y en la historia", apud Hidditsch, P. H. (ed.) (1975): 100-144.

Hidditsch, P. H. (ed.) (1975): Filosofia de la ciencia. México, F. C. E.

Jiménez Ruiz, J. L. (1994): Semántica sintomática. Propuestas para una hermenéutica comprensiva del sentido. Alicante, Universidad de Alicante.

Jiménez Ruiz, J. L. (2001): Iniciación a la Lingüística. Alicante, Editorial Club Universitario.

Kristeva, J. (1988): El lenguaje, ese desconocido. Introducción a la Lingüistica. Madrid, Fundamentos.

Kuhn, T. S. (1981): La estructura de las revoluciones cientificas. México, F. C. E.

Kutschera, F. von (1979): Filosofia del lenguaje. Madrid, Gredos.

Lakatos, I. (1974): Historia de la ciencia y sus reconstrucciones racionales. Madrid, Tecnos.

Laudan, L. (1986): El progreso y sus problemas: hacia una teoria del crecimiento cientifico. Madrid, Encuentro.

Laudan, L. (1993): La ciencia y el relativismo: controversias básicas en Filosofia de la ciencia. Madrid, Alianza.

Lenk, H. (1988): Entre la Epistemologia y la Ciencia social. Barcelona, Alfa.

López Cerezo, J. A. (1995): "El conductismo skinneriano como Filosofia de la ciencia y como Filosofía política", Revista de Historia de la Psicología, 16/I-II, págs. 211-240.

Losee, J. (1991): Introducción histórica a la Filosofia de la Ciencia. Madrid, Alianza.

Mardones, J. M. (1991): Filosofia de las ciencias humanas y sociales. Materiales para una fundamentación científica. Barcelona, Anthropos.

Martí Sánchez, M. (1998): En torno a la cientificidad de la Lingüística: aspectos diacrónicos y sincrónicos. Alcalá, Universidad de Alcalá.

Medawar, P. (1993): La amenaza y la gloria: reflexiones sobre la ciencia y los cientificos. Barcelona, Gedisa. 
Medina, E. (1989): Conocimiento y sociologia de la ciencia. Madrid, Centro de investigaciones sociológicas.

Meix Izquierdo, F. (1982): La dialéctica del significado lingüistico. Salamanca, Universidad de Salamanca,

Monserrat, J. (1984): Epistemología evolutiva y teoría de la ciencia. Madrid, Universidad Pontificia de Comillas.

Moulines, C. U. (1982): Exploraciones metacientificas. Madrid, Alianza.

Moulines, C. U. (ed.) (1993): La ciencia: estructura y desarrollo. Madrid, Trotta.

Muñoz, J. \& Velarde, J. (2000): Compendio de Epistemología. Madrid, Trotta.

Newton-Smith, W. H. (1987): La racionalidad de la ciencia. Barcelona, Paidós.

Ortega y Gasset, J. (1982): Meditación de la técnica y otros ensayos sobre ciencia y filosofia. Madrid, Revista de Occidente.

Polo, J. (1986): Epistemología del lenguaje e historia de la Linguiistica. Madrid, Gredos.

Popper, K. R. (1977): La lógica de la investigación cientifica. Madrid, Tecnos.

Popper, K. R. (1994): En busca de un mundo mejor. Barcelona, Paidós.

Rioja, A. (1996): "La Filosofia de la ciencia física de G. Berkeley", Themata, 17, págs. 145-165.

Rivadulla, A. (1995): "La revolución en metodología de la ciencia: Karl Popper (1902-1994) in memoriam", Endoxa, 5, págs. 7-33.

Rivas Monroy, Ma U. (1996): "Frege y Peirce: en torno al signo y su fundamento", Anuario Filosófico, 29/III, págs. 1211-1224.

Robles Ortega, A. (1997): La teoría del conocimiento en la tradición aristotélica. Granada, Universidad de Granada.

Russell, B. (1949): La perspectiva cientifica. Barcelona, Ariel.

Skinner, B. F. (1981): Conducta verbal. México, Trillas.

Valor Yébenes, J. A. (2000): Metodología de la investigación cientifica. Madrid, Biblioteca Nueva.

Wittgenstein, L. (1988): Investigaciones filosóficas. Barcelona, Crítica.

Zarco Rodas, A. \& Cozar, J. M. de (2001): "Hacer ciencia... sí, pero ¿cómo?" apud AA. VV. (2001): 45-59. 